\title{
Sergio Sismondo (2018) Ghost-Managed Medicine: Big Pharma's invisible hands. Manchester: Mattering Press. 231 pages. elSBN: 97809955277782
}

\author{
Jessica Mesman \\ j.mesman@maastrichtuniversity.nl \\ Dawn Goodwin
}

Sean Jensen

Pierre Springuel

Drug companies do everything they can to sell their products. This, in itself, is not surprising. After all, that's what businesses do. But do we really know what drug companies do and the extent of their influence? After reading Sergio Sismondo's book Ghost-Managed Medicine, we realised we knew only a fraction of what is really happening. Sismondo exposes pharmaceutical companies' extensive involvement in knowledge production. His arguments are compelling. Yes, one can read about how corporate-funded research tends towards publishing only favourable results, and about the fancy hotels and bonusses doctors receive when promoting the company's products. But this is not what the book is about. What GhostManaged Medicine is really about is the invisible ('ghost') orchestration ('managed') of medical knowledge production by the pharmaceutical industry.

This focus and scope of the book positions it in a strong STS tradition of opening the black box of the construction of scientific facts. Sismondo convincingly demonstrates how industry is involved in all aspects of medical knowledge production, circulation and consumption. Considering the secretive character of corporate activi- ties, it is impressive how the author has found his way into their political economies of knowledge production. Since many of company activities are outsourced and have to be promoted to their target groups (physicians) there is a highly-developed infrastructure of communication. It is in these promotion and educational meetings that Sismondo undertook ethnographic research. On the basis of this data he describes in detail what he calls 'assemblage marketing': how "a pharmaceutical company creates a market by producing, shaping and transporting research and medical journal articles, as well as opinion leaders and patient advocates. It pushes these in the expectation of influencing regulators, physicians, patients and other useful actors" (p. 23). Reading the book, it becomes clear how the pharmaceutical industry not only finance medical trials but are also involved in their design, in running the trials, undertaking the statistical analysis, writing the articles, selecting the journals and at the very end of the process inviting a well-known academic researcher to author the publication. This last move makes it almost impossible to distinguish the result from other academic research. Sismondo stresses that this in itself does 
not imply scientific flaws. The problem lies in the fact that scientific knowledge is entirely imbued with corporate interests that have been comprehensively removed from view. Research, in other words, acts as a Trojan horse for marketing.

However, the activities of drug companies do not stop here. Going beyond ghost-writing, Sismondo reveals how drug companies exert their influence in continuing medical education, through the co-opting and manipulation of 'key opinion leaders'. In some cases, drug companies even market symptoms and syndromes, initially in an 'unbranded' campaign, and as such shape public views of what to consider as healthy and unhealthy. Once need for a remedy is established, the product waiting in the wings can then quickly take centre stage. In this way drug companies penetrate doctors' consulting rooms, hospital wards, patient associations, and enter the thought-processes of patients.

The strength of this book lies in the detailed analysis of pharmaceutical companies' strategies of control over medical knowledge production - these are pervasive and unremitting, even to the point of aligning journal editors' interests with those of pharmaceutical companies. No stone is left unturned. The result is to completely undermine any semblance of objectivity in research and individual agency of doctors - both highly valued concepts in medicine. Where the book is weaker is in relation to the tactics of sales representatives. This chapter confirms suspicions but does not take our understanding beyond what one might expect. Nevertheless, we would like to suggest that 'doctors-to-be' should become aware of these processes. Being involved in the training of medical doctors and medical researchers we, Jessica Mesman and Dawn Goodwin, think that Ghost-Managed Medicine is an important text for students for the following reasons. Sismondo's book provides the means with which to teach students in the field of medicine core STS insights about the influences of the wider social and cultural context in which scientific knowledge is produced. The book illustrates the different relations between science and society, laying out in particular the role of industry and its complex and far-reaching influence. In this way, doctorsto-be and those who pursue a career in medical research become aware of corporate challenges to independence and the mechanisms through which industry exerts its influence in medical knowledge production on macro-, meso- and micro-levels. The book does all this with limited reference to sociological concepts and terminology. The connections to sociological bodies of work are clearly evident to those who would recognise them, and are explained explicitly in the opening chapter, but then the book speaks directly and plainly - an enormous benefit when teaching students who are required to develop social science understandings but without social science backgrounds.

To road test our view, we asked two students - Pierre Springuel and Sean Jensen - for their opinions:

Reading 'Ghost-managed medicine', for the first time in our careers, shed light on the pharmaceutical industry's veiled involvement in nearly all aspects of medical sciences. It describes the various interventions, hidden agendas and parties of the industrial machine involved in the creation, distribution and uptake of medical information. With responsibility as paramount as health, these supposed directors of our wellbeing are heavily scrutinised and approached with scepticism, we were keen to explore the extent to which this scrutiny and scepticism could be justified.

Reading the book, we were quickly faced with the reality that pharmaceutical companies control a significant portion of the information that professionals and public alike can access. Methods range from data manipulation, ghost-writing and public censorship to the recruitment of prestigious clinicians, researchers and communication companies to mindlessly parrot pharmaceutical agendas. To our dismay, it became blatantly evident we were ignorant of these ongoing practices, especially as biomedical students destined to one day become actors on Big Pharma's stage.

These crafty and manipulative conducts need to be recognised by the general public, and especially by future medical practitioners and researchers who often unknowingly act as marionettes of the pharmaceutical industry. We feel that the way to most effectively integrate this reality for the benefit of both the public and the industries is 
for attention to be brought on these issues. We believe this to be especially important for the next generation of scientists in the medical industry - us.

We advocate open discussion of the complicated issues brought up by Sismondo in small group seminars. There are no simple answers to the ethical concerns that arise with the pharmaceutical industry's influence, and so discussion is key. Discussing these matters in a critical manner, dissecting the problems and potential solutions, not only exposes but educates students on the current workings. The point of discussion is not to "solve the issue", but to critically evaluate arguments so that we can be aware and hopefully make well-informed decisions. We believe this to be the best way to equip students with the tools necessary to act in a more ethical manner when challenged by exogenous pressures.
So students and tutors agree - this book holds important lessons for future medical practitioners and researchers, those who value the objectivity of medical research and their independence as decision-makers. 